\title{
Pedagogia da contextualização e interculturalidade na formação de professores indígenas: entrevista com Maria do Socorro Pimentel da Silva
}

\author{
Lilian Abram dos Santos ${ }^{1}$
}

DOI: http://dx.doi.org/10.20435/tellus.v0i42.681

Atualmente, existem em torno de 25 cursos de licenciatura indígena no Brasil, destinados exclusivamente à formação de professores indígenas ${ }^{2}$. Tais cursos decorrem da agenda de lutas contínuas do movimento indígena por uma educação intercultural, que começou muito antes da vigência da Constituição Federal de 1988. Território, saúde e educação são os eixos que compõem a resistência indígena ao demorado e incansável processo de colonização que submete os saberes e corpos indígenas historicamente. Felizmente, nos últimos 15 anos, como decorrência das ações do movimento indígena e da implantação das ações afirmativas para outros grupos desfavorecidos, muitas universidades e institutos federais reconheceram sua responsabilidade no processo de exclusão de sujeitos e coletivos minorizados e se mobilizaram para a elaboração de cursos superiores de formação de professores indígenas cujos objetivos são o de contribuir para a construção de uma educação não colonizadora, na qual os saberes indígenas estejam presentes no currículo, nos materiais didáticos e nos projetos pedagógicos das escolas indígenas.

O curso de Educação Intercultural do Núcleo Takinahakỹ de Formação Superior Indígena, da Universidade Federal de Goiás, é uma licenciatura específica para a formação de professores indígenas, iniciada em 2007. O curso atende, atualmente, estudantes de 27 povos indígenas, dos estados de Goiás, Maranhão, Mato Grosso e Tocantins, sendo um exemplo da possibilidade de realização de uma educação escolar indígena verdadeiramente intercultural, bilíngue, específica e diferenciada e, antes de tudo, com o objetivo de romper com o histórico de educação assimilacionista e colonizadora.

1 Universidade Federal de Goiás (UFG), Goiânia, Goiás, Brasil. 
Maria do Socorro Pimentel da Silva esteve à frente da criação do curso de Educação Intercultural. Devido à sua extensa experiência como docente na educação escolar indígena, Maria do Socorro pôde, há 12 anos, conceber, juntamente de representantes indígenas e docentes da UFG, um projeto pedagógico inovador, no sentido de não somente se preocupar com a formação de professores, mas, sobretudo, de se lançar na aventura de compor uma nova base epistêmica para as escolas indígenas e para a própria universidade.

Maria do Socorro Pimentel da Silva é pedagoga, mestra em Letras e Linguística pela UFG e doutora em Linguística Aplicada ao Ensino de Línguas pela Pontifícia Universidade Católica de São Paulo (PUC-SP). Tanto no mestrado quanto no doutorado realizou pesquisas junto ao povo Karajá. Fez seu estágio de pós-doutorado na Unicamp e, em fevereiro de 2019, tornou-se professora titular da Faculdade de Letras da UFG. Com o projeto Maurehi, na aldeia Buridina do povo Karajá (GO), foi uma das pioneiras nos estudos e nas pesquisas de revitalização linguístico-cultural no Brasil³. Também demonstrou postura visionária ao criar a Revista Articulando e Construindo Saberes ${ }^{4}$, cujo escopo é a publicação de pesquisas relacionadas à decolonização de saberes e às práticas pedagógicas pluriepistêmicas e interculturais.

Entrevistadora: Professora, conte-nos um pouco sobre como, durante sua juventude, morar numa aldeia Karajá influenciou o trabalho que exerce hoje como docente no curso de Educação Intercultural.

Profa. Maria do Socorro: Se eu não tivesse passado por essa primeira experiência de ser professora numa escola indígena, acho que eu não teria condições e nem capacidade para refletir e pensar, por exemplo, num curso de educação intercultural.

3 Parte do Projeto Maurehi está documentada em PIMENTEL DA SILVA, Maria do Socorro. Reflexões sociolinguísticas - sobre línguas indígenas ameaçadas. Goiânia: Editora da UCG, 2009.

4 Disponível em: https://www.revistas.ufg.br/racs. 
Vou retomar um pouco a minha chegada à aldeia Karajá. A primeira aldeia Karajá em que morei foi a aldeia Fontoura, na Ilha do Bananal, TO. Eu me lembro até hoje do dia em que eu cheguei a essa aldeia. Algo que me marcou muito. Um avião bimotor pousou, a comunidade inteira estava no campo de pouso e eu me encontrei com pessoas alegres, felizes e animadas. E eu assustada. Foi muito difícil para mim, primeiramente, porque não sabia falar nada em Karajá. Nunca havia escutado essa língua. Na realidade, eu nem sabia que existiam línguas indígenas. Depois de uns quatro meses, eu pedi para voltar para perto da minha família e sair da aldeia. Não por conta dos indígenas, mas eu não conseguia me conectar àquele local. E, nessa ocasião, um professor Karajá, que na época ainda era chamado de monitor bilíngue, percebendo a minha aflição, ofereceu-se para me ensinar sua língua. Eu aceitei e ele me ensinou na fala masculina. O Karajá é uma língua que tem diferenças morfológicas/fonológicas entre a fala de homens e mulheres. Daí a primeira vez que eu fui para aldeia conversar, a comunidade inteira ficou rindo de mim, e isso me deixou desesperada. Fiquei muito triste.

Ao retornar para a cidade e morar perto da minha família, algo aconteceu comigo, dentro de mim. Hoje, interpreto que foi algo como um ritual de iniciação, de entrada na sociedade Karajá. Na época, eu não sabia o que estava acontecendo. Hoje, recordando, eu sei que foi exatamente isso que aconteceu. Eu passei por um processo ritual, porque fui eu quem desejou voltar e trabalhar na aldeia. Voltei para a aldeia Itxalá, onde morei e fui professora por muitos anos. Nessa aldeia, aprendi a ser professora, aprendi a dar aulas, a pesquisar sem saber que estava pesquisando, a construir material didático sem saber que estava fazendo. Convivi com as mulheres que me aceitaram no seu grupo e passei a ter companheiras que me ensinavam muito. Por exemplo, eu ia com elas coletar frutas e aprendia o nome das frutas, em Karajá, na experiência de coletar frutas. Eu contei muito com o apoio dessas mulheres que não sabiam nem ler, nem escrever, mas que foram, elas, as minhas professoras, na minha formação de ser professora.

Houve também uma liderança, um sábio indígena, que participava, inclusive, de reuniões em Brasília, que me ensinou muito. Eu estava estudando a língua a partir de uma cartilha produzida por missionários do Summer Institute of Linguistics (SIL). Quando li alguns trechos da cartilha, ele me falou que aquela não era a língua dele, "Essa não é a minha língua. Você já ouviu alguém falando assim aqui na aldeia?". E disse que, se eu quisesse aprender a língua, deveria ir 
todos os dias em sua casa, sentar na esteira, comer peixe, tartaruga, que, assim, eu aprenderia.

O que eu aprendi na convivência com essa família, além de questões linguísticas e culturais, foi como esse povo pensa, como os Karajá pensam o mundo, interagem com sua família, com a comunidade. Aprendi com eles o que eu chamo de pedagogia da cordialidade, o que um tem, todos têm. Com eles, eu aprendi muita coisa. A dar aulas, como compartilhar, como viver na amizade. Também aprendi a conviver no conflito, porque presenciei situações de muitos conflitos internos, o que me deixou muito triste.

Algo de muito precioso da minha experiência na aldeia Itxalá foi a minha formação como professora numa situação em que as crianças falavam uma língua e eu outra. Essa é uma experiência inesquecível.

E como eu atuava nessa situação? Tudo que eu aprendia com as mulheres fora da escola eu levava para a escola. Então, uma simples palavra na língua Inỹ se tornava muitas outras palavras. As crianças colaboravam no "esticamento" daquela palavra, porque aquela palavra era muito mais do que uma palavra. Era um tema. E esse tema estava ligado com outros temas da vida daquelas crianças. Então, desde essa época, eu aprendi o que é trabalhar uma pedagogia da contextualização, aprendi a escutar o que o outro sabe e o que é aprender nesse processo de escuta. Dificilmente você ensina alguém se você não aprender com ele também.

A experiência que eu tive com os Karajá não foi uma experiência acadêmica. A experiência acadêmica é muito interessante, mas ela não te ensina a como voltar para o mundo do outro. Na universidade, você se dedica muito a um projeto seu, a uma formação sua, do indivíduo. Numa comunidade indígena, o projeto não é seu. Ele é coletivo, da comunidade.

Entrevistadora: A senhora fala de pedagogia da contextualização quando ensinava as crianças a partir de palavras-tema, num contexto sociolinguístico em que a língua das crianças não era compartilhada pela professora. Os temas contextuais que organizam e estruturam a matriz curricular do projeto pedagógico do curso de Educação Intercultural da UFG têm sua origem aí? Parece haver uma relação entre ambos... 
Profa. Maria do Socorro: De fato, há uma relação. Eu aprendi na escola que eu não sabia falar a língua, não tinha material. Também percebi que tudo naquela comunidade era vivido, tudo era na interação, na troca. Fui percebendo essa pedagogia, que, agora, estamos chamando de contextualização... A palavra que eu aprendia com as mulheres eu levava para a escola, e essa palavra se conectava com muitas outras palavras, o que me dava um texto oral. Eu começava com a palavra em Karajá, mas eu também esticava para a língua portuguesa. Aliás, foi assim que eu trabalhei a língua portuguesa com eles, sempre partindo da língua Karajá. Não que eu tivesse uma concepção definida de ensino, mas era o que eu conseguia fazer naquele momento. Eu aprendi muito com essa experiência e os alunos da escola também. Aprendemos juntos.

Outra experiência aliada a essa foi o Projeto Maurehi, na aldeia Buridina. Um projeto de reconstrução de espaços culturais e epistêmicos.

Essas duas bases de conhecimento foram fundamentais para eu pensar nos temas contextuais, porque o tema contextual favorece o protagonismo de todos os que estão presentes ali no momento do ensino-aprendizagem, uma vez que evidencia o processo de troca da aprendizagem. Foi assim com as palavras na aldeia Itxalá, quando eu sabia um pouquinho da língua e da cultura Karajá, quando meu papel não era ensinar a língua Karajá, e sim a língua portuguesa, eu começava sempre de uma realidade contextual. E deu certo. O tema contextual, além de favorecer o movimento emancipador de retomada dos saberes indígenas, de conectar a escola, ou a universidade, com os modos e espaços de produção do conhecimento indígena, favorece a articulação entre conhecimentos, sem desprezar o conhecimento indígena.

O tema contextual pode ser intracultural, focado somente no conhecimento indígena, mas ele pode ser alongado, como eu fazia com as palavras em Karajá que nomeavam frutas e eu as esticava para temas da língua portuguesa, para ensinar português.

O mesmo acontece com os temas contextuais do curso de Educação Intercultural. É possível começar com um tema intracultural, em língua materna, e articular esse tema com outros conhecimentos. Do mesmo modo, pode-se trabalhar um tema contextual somente na língua portuguesa, ou de forma bilíngue, que nós chamamos, no Núcleo, de bilinguismo intercultural. Ou, ainda, inicia-se 
um tema contextual em português e se o articula com os conhecimentos indígenas. Então, há liberdade de composição e articulação que não existe no trabalho pedagógico estruturado a partir das disciplinas. A minha experiência pedagógica se deu e se dá muito mais pela contextualização do conhecimento do que pelas disciplinas. Eu nunca fui professora da educação básica para não indígenas, eu sempre trabalhei com povos indígenas. Por exemplo, um grande desejo deles era aprender matemática, principalmente dos adultos. Quando a gente pensa em alfabetização, a gente pensa em textos, jogos... a minha experiência com alfabetização foi por meio da matemática. Os pescadores Karajá vendiam os pirarucus que pescavam e eram explorados nesse processo, então vieram me procurar dizendo que queriam ser alfabetizados. E disseram que queriam aprender troco, lucros, exploração, contas. Mais uma vez, um conjunto de palavras ia construindo um projeto de alfabetização para atender à demanda dos pescadores de pirarucu.

Acredito que o trabalho com temas contextuais remonta toda essa experiência, mas, mais do que isso, cabe perceber que o outro também é parte desse processo pedagógico. O projeto pedagógico não é meu, é de quem o solicita.

Entrevistadora: Sabemos que desde a educação jesuítica - a primeira experiência de escola colonizadora para indígenas - as línguas indígenas são tratadas apenas como línguas de transição para a língua portuguesa. Missões religiosas e propostas do próprio Estado efetivaram o que chamamos de bilinguismo de transição, que é o uso da língua indígena para a alfabetização e o acesso à escrita, para, logo depois, o ensino ser em língua portuguesa. Como a senhora vê saídas para que a escolarização possa ser parte de uma política linguística ampliada de valorização e fortalecimento das línguas indígenas, em suas modalidades oral e escrita, e não uma armadilha para deslocar e diminuir os espaços de uso dessas línguas?

Profa. Maria do Socorro: Bom, vou começar a responder de um modo mais geral. Todos nós sabemos que a globalização dos valores econômicos, sociais e culturais impulsionada pelo desenvolvimento tecnológico oprime as línguas indígenas. Em decorrência dessa realidade e da ameaça de extinção das línguas indígenas, o curso de Educação Intercultural da UFG tem buscado construir bases epistêmicas que apontam para diretrizes inovadoras no campo de educação intercultural de valorização das línguas indígenas. Vou citar quatro referências de 
políticas linguísticas fortes para o processo de formação de professores no curso de Educação Intercultural da UFG: Temas Contextuais, Estudos Complementares, Projetos Extraescolares e Estágios.

Antes de eu falar especificamente a respeito da relação entre política linguística e esses quatro componentes, nós precisamos retomar a discussão de valorização das línguas indígenas com o compromisso de enfrentarmos muitos desafios, pois essa é uma questão que diz respeito à Educação, ou seja, vai muito além das Ciências da Linguagem. É uma questão de política de valorização das línguas indígenas, dos saberes indígenas e de respeito aos povos indígenas. Sendo assim, quero trazer uma reflexão, sobre a qual eu já escrevi e continuo pensando muito sobre isso.

Nossa visão disciplinar vertical dificulta contextualizar as realidades necessárias para o debate. Todos nós sabemos que, na realidade, todos os cursos de formação de professores conhecem muito pouco das línguas indígenas brasileiras. Conhecem menos ainda a situação em que essas línguas se encontram contemporaneamente, a situação entre as gerações, os locais onde as línguas são faladas, quais saberes elas guardam, quais espaços linguísticos são apagados, desatualizados, extintos. Quais são os usos mais especializados dessas línguas, como elas são usadas na vida cotidiana, entre as gerações, nas famílias. Quais saberes existem e quais foram extintos. Essas são reflexões importantes para entendermos a importância de uma política linguística forte a ser colocada em prática nos Temas Contextuais, nos Projetos Extraescolares, nos Estágios e nos Estudos Complementares. Por isso nós precisamos ter um estudo aprofundado do que, para mim, é muito mais do que uma situação sociolinguística, uma vez que nós conhecemos também pouco das ciências indígenas. Por falta do conhecimento das ciências indígenas, elas são apelidadas a partir da perspectiva das ciências científicas, algo a que sou totalmente contrária. Isso acontece em todos os lugares e também no curso de Educação Intercultural da UFG, infelizmente. Esses são pontos importantes para, de fato, firmarmos o compromisso de elaboração e desenvolvimento de políticas linguísticas fortes no espaço do curso e também em outros espaços, como, por exemplo, a escola.

Dito isso, vamos retomar os quatro pilares do curso. O Tema Contextual, como eu sempre falei, é uma composição, uma articulação de conhecimentos e um contexto de problematizações. Ele é que reivindica as línguas que serão usadas. 
Depende se o tema será intracultural, o qual se articula dentro do universo de cada povo indígena, principalmente dos conhecimentos do campo do sagrado e dos saberes especializados. No entanto, ao mesmo tempo, muitos conhecimentos que são primeiramente reconhecidos como pertencentes ao campo dos saberes especializados, ao se esticarem, se articulam com os conhecimentos ocidentais e, aí, nós passamos a ter os temas interculturais. Esses conhecimentos podem ser trabalhados nas línguas indígenas, de modo bilíngue ou, até mesmo, somente na língua portuguesa. A educação é bilíngue, então, poderá haver vários movimentos, e esses movimentos romperão exatamente com aquilo que você me perguntou. Esses movimentos rompem com o império do monolinguismo, que foi chamado, por volta dos anos 1970, como bilinguismo de transição, mas que nada mais é do que uma ponte para o monolinguismo. Uma ponte para a introdução da escrita, para romper barreiras linguísticas a serviço do monolinguismo.

Outra política linguística forte que rompe com o assimilacionismo são os Estudos Complementares. Sem me alongar muito, quero falar do estudo complementar Português Intercultural, que, como o próprio nome já diz, coloca o português em relação a outros contextos de vivências. Em relação às línguas indígenas, a novos contextos de demandas e de articulações. É um português intercultural, e não um português indígena, como é o caso de muitas outras abordagens para o português que temos visto no Brasil. É um português de atendimento de demandas ou, como disse uma vez um estudante Kanela, um português da precisão. Por isso o Português Intercultural está sempre relacionado às demandas do sujeito bilíngue. O que também é uma política linguística, uma vez que as línguas indígenas estão nessa composição.

Já os estudos complementares de Línguas Indígenas são estudos de línguas indígenas, e não de teoria linguística. É claro que a linguística é importantíssima, mas nesses estudos complementares nós contextualizamos a comunicação entre as gerações, os espaços sagrados, os segredos, o cotidiano, as falas mais especializadas. Há uma política de valorização das línguas indígenas, a partir da valorização da oralidade dos saberes tradicionais e, sobretudo, da valorização do papel dos sábios e sábias, dos anciãos e anciãs, dos artesãos e artesãs nesse processo de conhecimento semântico, contextual, cosmológico da língua. Tudo isso precisa ser apropriado pelos estudos em Línguas Indígenas, superando uma 
tendência colonialista e eurocêntrica que exclui as línguas indígenas quando se trata de línguas de conhecimento.

O Projeto Extraescolar é uma política linguística muito forte de retomada de conhecimentos, mas também de criação de outras epistemologias. Quando um estudante está pesquisando com os mais velhos, documentando aquele conhecimento através da escrita ou da oralidade, está ocorrendo não somente um processo de reflexão sobre o conhecimento, mas a própria produção de conhecimentos outros que não são mais conhecimentos tradicionais indígenas, mas que são conhecimentos os quais estou chamando de epistemologias interculturais, ou de coteorização, pois criam novos referenciais. Por exemplo, a retomada de saberes surge nesse contexto. A retomada de saberes ancestrais, a qual traz consigo a retomada de outras lutas, ocorre por meio das línguas indígenas também, pois língua e conhecimento fazem parte de um mesmo corpo cultural. Toda essa orientação aponta para uma necessidade de aportes coteóricos e metodológicos de visibilidade das epistemologias indígenas e das pedagogias de articulações epistêmicas. Somente os espaços tradicionais, hoje, ainda que sejam uma parte muito importante, não são suficientes. Há necessidade de outras criações dentro das relações interculturais, ou, como os indígenas explicam, da atualização.

Há políticas linguísticas indígenas fortes muito importantes, desde a criação de palavras para nomear novas realidades até o estudo das diferenças entre fala masculina e fala feminina, porque tudo isso dá um grande referencial teórico, e coteórico, para a implantação de políticas linguísticas e, também, para a produção de materiais didáticos.

As pesquisas por meio dos Projetos Extraescolares, ou por meio de outros projetos, estão trazendo respostas muito importantes para a adoção de políticas linguísticas, ou dentro do contexto da escolarização, ou para a escola adotar políticas linguísticas de articulação entre os espaços epistêmicos, sejam os tradicionais ou não, entre escola e comunidade.

Outro referencial de política linguística forte da Educação Intercultural é o Estágio, porque, nos estágios, o bilinguismo adotado é muito diferente do bilinguismo de transição. Os estágios possibilitam o bilinguismo da pluralidade. Nós podemos chamá-lo de bilinguismo epistêmico, porque ultrapassa a prática de pensar nas línguas desvinculadas dos conhecimentos, afinal, as línguas são línguas 
de conhecimentos e estão na produção dos conhecimentos, se articulando com a língua portuguesa e com as diferentes ciências. O estágio está criando uma proposta de educação bilíngue e interepistêmica, conjuntamente com todos os outros referenciais sobre os quais eu falei. Eu sou da opinião de que há espaço dentro desse contexto para as línguas indígenas, não somente dentro do bilinguismo, mas há um espaço próprio. Eu quero considerar que as línguas indígenas são línguas ameaçadas, ninguém tem dúvidas disso, então eu sempre estou pensando na criação de outros espaços específicos para as línguas indígenas, tais como projetos de extensão das escolas, com outras demandas de valorização, como, por exemplo, jogos pedagógicos, que estão sendo elaborados pelos Karajá e por outros povos, para as crianças frequentarem essas línguas e acessarem os conhecimentos que estão apagados. Os indígenas estão criando possibilidades para as crianças acessarem a linguagem especializada. Eu considero tudo isso muito importante, porque a língua tem outras dimensões para além da dimensão linguística. As línguas indígenas também passam por momentos de discussão da escrita. Essa discussão também pode ser vista de modo intercultural.

Eu coordeno o projeto "Práticas decoloniais de letramentos em línguas indígenas" e tenho observado diversas funções e razões das línguas indígenas no processo de decolonização, por exemplo, os Projetos Extraescolares. É comum ouvirmos de nossos estudantes afirmações como "eu não conhecia esse fato do meu povo" ou "eu não sabia que essa regra existia". A ideia de criar contextos para a criança acessar e aprender conhecimentos, como, por exemplo, nomes de frutas, que as crianças só sabem em português. É muito importante problematizarmos essa situação, pois é admissível que usem o português para nomear as frutas, mas que essa prática não mate o nomear na língua materna. A escrita está ajudando a movimentar a oralidade, a relembrar conhecimentos. Uma vez eu distribuí um livro de histórias Karajá em Buridina. Como pesquisadora e curiosa, eu voltei à aldeia no final do dia e, para minha surpresa, as pessoas estavam lendo o livro, relembrando as histórias, relembrando de seus avós. Eu também vejo a escrita em língua indígena na produção de textos coteóricos, como podemos encontrar na Revista Articulando e Construindo Saberes. Há textos de conhecimentos tradicionais e há um texto sobre fonologia escrito em língua Iny/Karajá. 
Entrevistadora: Professora, os temas contextuais, pelo que entendi, fazem parte de uma proposta maior do curso que consiste em não operar com a noção de disciplina. Inclusive, os temas contextuais são a metodologia utilizada para o desenvolvimento dos estágios realizados pelos estudantes durante o curso. Os temas contextuais podem ser realizados tanto na língua indígena como no português, como nas duas. Ele traz para a sala de aula os conhecimentos e saberes indígenas. Além dos temas contextuais, quais outras características do curso de Educação Intercultural são relevantes para compor uma matriz de conhecimentos indígenas?

Profa. Maria do Socorro: Quando você fala de conhecimentos indígenas, você está falando de conhecimentos ancestrais e tradicionais ou não?

Entrevistadora: Estou me referindo ao que parte do corpo docente do curso de Educação Intercultural tem chamado de novas bases epistêmicas.

Profa. Maria do Socorro: Eu penso que são várias características, mas o curso tem uma composição que favorece sempre a articulação, sempre o movimento. E o curso tem duas ações que eu coloco sempre em destaque. O Tema Contextual, sobre o qual nós terminamos de falar, e o Projeto Extraescolar. O Projeto Extraescolar nasceu desse desejo mesmo de reconhecer que as línguas indígenas estão ameaçadas de extinção, de entender, como linguista, que as línguas indígenas, como qualquer outra língua, são muito importantes para seu povo, não somente para a educação das gerações ou para a comunicação familiar, mas para outras conexões que são fundamentais para a manutenção do ser. Como cantar um hetohokỹ em língua portuguesa? Não tem como! Como chorar, fazer um canto de lamento pela morte de alguém em língua portuguesa? Não tem como fazer em língua portuguesa. Conhecendo essas características, que não são pertinentes somente aos indígenas, mas são eles o nosso assunto, como colocar num curso de educação intercultural dentro de uma universidade alguma ação, alguma composição curricular que pudesse transitar por esses lugares que eu acabei de falar? Um dia, um indígena me disse assim: "Se eu perder a minha língua, como eu vou me comunicar com minha ancestralidade? Quando eu morrer, como eu vou encontrar os meus?". Essas são reflexões profundas que, muitas vezes, a Linguística não traz, mas os indígenas trazem.

O projeto extraescolar é a ação de o próprio indígena pesquisar o conhecimento do seu povo. E nós temos percebido, durante esses doze anos de curso, que 
uma característica fundamental do projeto extraescolar é a retomada dos saberes ancestrais. A reconstrução de muitos espaços epistêmicos que foram apagados, destruídos, silenciados. O avivamento desses espaços culturais não acontece sem as línguas. E se o indígena falasse sua língua somente em espaços cotidianos, ele perderia a conexão com a ancestralidade, a espiritualidade. Como diz Manajè Karajá, o mundo tem várias camadas, porque tem essa camada mais próxima, que é a camada do cotidiano, mas tem outras camadas, como, por exemplo, quando um indígena chega perto de uma árvore e pede licença ao ente muito sabido da espiritualidade que acompanha essa árvore, para tirar a casca ou a folha para virar remédio. Nós temos aprendido com os indígenas que o remédio não é somente aquela folha ou aquela casca. O remédio tem a ver com alguma coisa que a gente não vê na folha, mas é uma substância que está lá.

O projeto extraescolar tem como um de seus objetivos o de formar o professor junto a sua comunidade e também de trazer para a universidade esses conhecimentos, estabelecendo uma relação de diálogo entre a universidade e os espaços culturais ou epistêmicos. As comunidades ganhariam, como também a universidade, porque um canal muito interessante entre saberes foi aberto. Durante esses doze anos, nós percebemos muitos indígenas dizendo "Eu não sabia que minha comunidade tinha tanto conhecimento", "Eu não aprendi isso quando eu era jovem".

Uma vez, um aluno Karajá pegou um livro que foi publicado por nós, leu uma história e me pediu aquele livro. É um livro escrito em Karajá, nas falas masculina e feminina, e em português. Ele leu aquela história para sua avó, na aldeia, e sua avó começou a lembrar daquela história e a contá-la. Então, o projeto extraescolar também é isso: relembrar conhecimento, estabelecer conexões. O rapaz nos disse que sua avó não havia Ihe contado histórias porque não era o tempo que a avó contava histórias e que iria fazer a experiência de contar para seus filhos. E contou para seus filhos, lendo o livro, e as crianças dormiram muito felizes.

O Projeto Extraescolar não chama assim por acaso. Ele é muito mais do que uma etapa da formação do professor. Ele é uma retomada do processo de formação do ser indígena. E há outra coisa muito importante. Quando esses indígenas aprendem esses saberes, eles formam os mais jovens, criando uma outra geopolítica para seus conhecimentos. Eles vão se formando cada vez mais. 
E o indígena, ao fazer o extraescolar, se coloca como protagonista da nossa formação, dos professores não indígenas, havendo um desmanche dos papéis de formadores. Todos nós somos formados e formadores ao mesmo tempo. Além disso, saem ideias fantásticas dos projetos extraescolares, que irão compor uma base epistêmica que vai muito mais além da leitura dos autores decoloniais. São reflexões que criam propostas para uma educação específica e diferenciada, que foi desejada, e não apenas legitimada por uma lei. São os indígenas que estão desejando, que estão compreendendo, na profundidade, a importância que isso tem. É muito bonito.

Para finalizar, uma das características mais importantes desse curso são as bases epistêmicas que os indígenas e nós, não indígenas, estamos construindo. É isso o que eu tenho chamado de coteorização. Além da certeza de que eles podem construir uma escola para atender às suas demandas, que não são apenas demandas de retomada de saberes ancestrais, mas são a retomada do convívio com a sociedade não indígena de maneira mais segura, sem se sentirem inferiorizados, mas sim diferentes e participantes do debate.

Entrevistadora: Não poderíamos deixar de conversar também sobre a política de egressos do curso de Educação Intercultural. Como os docentes têm conseguido acompanhar a trajetória dos egressos do curso?

Profa. Maria do Socorro: Por força das circunstâncias, o curso adotava e ainda adota uma política de egressos muito interessante. Por exemplo, convidar egressos para dar aulas de estudos complementares de Línguas Indígenas ou mesmo de temas contextuais é uma oportunidade para que eles possam contar suas experiências para os atuais estudantes do curso. Contar toda a história de como eles foram aprendendo, refletindo e construindo a sua maneira de discutir educação intercultural é muito interessante. Outro aspecto muito interessante é a participação deles em congressos. Professores têm levado estudantes egressos para participarem de congressos em outros estados para conviverem com outros pesquisadores e participarem do debate, compartilhando suas experiências. Outro componente da política de egressos é a produção de material didático, que acontece também por meio de outros projetos, como o Pibid. Essa política de egressos acontece também na própria aldeia quando eles estão compartilhando, 
entre eles, suas pesquisas. Por exemplo, como produzir um livro para alfabetização. Entre os Karajá, eles acharam bom produzir um livro de alfabetização tendo como eixo a ecologia. Segundo eles, as crianças estão se distanciando de muitos conhecimentos ligados à natureza e, diante dessa observação, resolveram produzir um material didático que retomasse esse conhecimento por meio de suas próprias pesquisas.

Um ponto que considero fazer parte da política de egressos é o apoio desses ex-alunos do curso no movimento indígena, nas discussões em defesa aos direitos indígenas e à educação escolar indígena. Eles(as) estão envolvidos(as) na luta e na defesa por uma educação escolar indígena intercultural, específica e diferenciada.

E algo muito bacana é o desejo dos egressos em continuarem seus estudos. O curso de Especialização Educação Intercultural e Transdisciplinar: gestão pedagógica é fruto desse desejo. Os formandos das primeiras turmas, de 2007 e 2008, ao concluírem o curso, solicitaram uma especialização, porque eles queriam continuar discutindo os projetos político-pedagógicos de suas escolas, uma vez que a maioria das escolas desses professores nunca teve um projeto político-pedagógico próprio. Os Estágios permitem aos nossos estudantes a experiência da construção de uma base epistêmica que pode ser utilizada na construção do projeto político-pedagógico das escolas de suas aldeias. Agora, o desdobramento desse desejo de continuar os estudos está sendo a criação do Mestrado em Educação Intercultural.

Entrevistadora: Para encerrar nossa entrevista, eu gostaria que a senhora falasse um pouco sobre como tem sido a experiência de coteorização com professores indígenas dentro do Núcleo Takinahakỹ de Formação Superior Indígena, uma vez que essa é uma questão que tem se tornado cada vez mais relevante tanto para o debate decolonial quanto para a insurgência de novas epistemologias.

Profa. Maria do Socorro: Eu não sei se posso, de fato, responder por todo o Núcleo, mas vou falar sobre minha experiência de coteorização com os professores indígenas do Núcleo. Para isso, vou retornar à primeira turma de 2007. Essa era uma turma de 50 estudantes, todos muito críticos e problematizadores, que desafiaram todos nós na construção de uma educação intercultural. Os estudantes eram de sete povos diferentes e os docentes não indígenas eram de diversas áreas, 
e quase nenhum possuía experiência com educação escolar indígena. Durante uma reunião, em que todos os estudantes e docentes estavam, e na qual discutíamos os princípios de interculturalidade e decolonização, um estudante Karajá levantou e disse que, da forma como o curso estava sendo organizado, nós, os docentes, seríamos os novos colonizadores. No entendimento desse estudante, o curso estava sendo concebido como uma imposição, porque era um curso muito diferente de todos os outros cursos de graduação. Essa fala foi um murro no meu coração, porque nós havíamos passado dois anos discutindo o projeto do curso com as comunidades indígenas, a fim de achar caminhos possíveis para a interculturalidade e a decolonialidade. O fato de ter vindo de um estudante Karajá me impactou ainda mais. No entanto eu pensei que ele estava muito certo do que estava dizendo e propus que os professores não indígenas saíssem da sala e os estudantes discutissem, ou coletivamente ou cada um com seu povo, o que gostariam de sugerir a nós. Primeiramente, eles se organizaram por povos, depois coletivamente e, então, nos chamaram e disseram que iriam esperar mais um pouco, para terem tempo de conhecer o curso. E, de fato, eles se animaram com o curso, sobretudo com a matriz específica, quando tiveram a oportunidade de entender a nossa proposta. E, durante os primeiros dois anos da matriz básica, nós fomos construindo coletivamente os caminhos do curso.

Também durante a conferência de abertura de um congresso em Cochabamba, ouvi o ministro da Educação, um Aymara, dizer que, para fazermos educação intercultural, primeiramente é preciso conhecermos a colonialidade do saber.

Fiz esses relatos para eu poder explicar melhor o que nos fez pensar em coteorização, como desafios e caminhos possíveis. Uma pergunta que sempre me faço, e que me proporciona uma reflexão sobre coteorização, é como fazer educação intercultural tendo apenas a base de conhecimento ocidental? Quando um curso é disciplinar, com organização predominantemente ocidental, não temos uma educação intercultural, e sim uma educação colonizadora. A pergunta principal que eu me faço é: o que de fato é uma educação intercultural?

Atualmente, muitas universidades contam com programas de ações afirmativas para a inclusão de indígenas, quilombolas e outros segmentos da sociedade que sempre foram mantidos à margem. No entanto eu percebo que são programas de inclusão que acabam por excluir, uma vez que têm como base uma organização 
curricular e política que, de fato, não inclui os indígenas. Não é tão difícil oferecer vagas extras ou por cotas, mas o desafio maior não é esse. O desafio maior é construir currículos que dialoguem com os saberes de indígenas, quilombolas, pescadores e todos os outros. A educação intercultural tem por obrigação não adotar um sistema de inclusão para a exclusão. A educação intercultural deve ser um sistema decolonial, coteórico, de diálogo, de composição e parceria.

Eu entendo a coteorização como um modo muito especial de pensar a educação, de pensar a construção de conhecimentos de forma articulada. No curso de Educação Intercultural do Núcleo Takinahakỹ, a coteorização ocorre a partir dos Projetos Extraescolares, das Ações Saberes Indígenas e dos Estágios. Esses são os três contextos possíveis para a coteorização. Nos Projetos Extraescolares, o primeiro plano de articulação dos saberes é a decolonialidade. Quando os saberes de cada povo são articulados para a retomada de espaços epistêmicos, para a retomada de saberes ancestrais, recriam-se novos saberes. O segundo plano dos Projetos Extraescolares é a articulação intercultural. Tanto no plano da articulação intercultural quanto intracultural surgem novos saberes, coteóricos, porque os saberes já não estão mais em seu campo milenar, esses saberes são fruto de uma reflexão a respeito de como eles podem integrar e contribuir com práticas pedagógicas, na composição das matrizes curriculares, no modo de construir um projeto político-pedagógico. Nós falamos tanto de processos próprios de conhecimento, mas devemos nos perguntar como esses processos vão para a escola. Esses saberes vão para a escola no modo como os indígenas pensam e constroem pedagogias e metodologias de acordo com suas experiências interculturais. Nesse momento, começa a haver a coteorização. O Projeto Extraescolar, além da retomada de saberes, o que por si só já é um processo decolonial, favorece a articulação intercultural no campo pedagógico.

O esforço da coteorização na formação de professores indígenas é bem diferente do esforço da coteorização colocado pelos autores decoloniais. A decolonização é sentida no corpo, na vida, na história e no fazer do presente. A retomada de saberes vem acompanhada das lembranças da colonização, mas também da alegria da atualização cultural. Os Karajá de Itxalá não faziam há mais de 40 anos o hetohokỹ, um dos seus principais rituais. Em 2019, eles conseguiram fazer o hetohokỹ por meio das pesquisas dos seus Projetos Extraescolares. 
O Estágio é outro contexto de coteorização. Quando, por exemplo, ao relatar seu estágio, um indígena me diz que primeiro fez sua aula prática, eu entendo que a aula prática sempre ocorre no campo do concreto, do fazer, da interação. Todos participam. Uns colocando aquele fazer à disposição de todos os aprendizes, e os aprendizes experimentando. Esse saber da aula prática é tecido pela oralidade e também pela observação, pela matéria-prima disponível, pelo evento cultural. Depois do processo da aula prática, é que vai acontecer a aula teórica, que é a aula da sala de aula, da escrita. A escrita não é o barro que eu manuseio para produzir conhecimento, ela está mais para o campo do abstrato.

A Ação Saberes Indígenas na Escola é um outro componente importante para a coteorização. Nela, as atividades são sempre desenvolvidas nas aldeias, e não nas universidades, e os pesquisadores indígenas têm outra temporalidade para organização de seus saberes.

A coteorização, no meu entendimento, não é uma teoria composta somente pelo Ocidente. É uma teoria composta por conhecimentos produzidos em outros modos. Como os próprios indígenas dizem, esses outros modos de conhecimento também se atualizam. Todos esses ingredientes, como a atualização cultural, a aula prática, a aula teórica, fazem parte de um campo coteórico. Eu a entendo de várias formas, tanto para a intraculturalidade quanto como uma contribuição para a vivência intercultural, que extrapola a questão indígena. É a descoberta de outros fazeres, de outros sentidos de fazer a educação. Qualquer conhecimento, com exceção do segredo e do sagrado, pode vir para a escola, porque não é uma escola ocidental. É uma escola que tem por base a coteorização, que é um outro jeito de fazer, que, por sua vez, tem por base a educação intercultural, que vai possibilitar a criação de novas práticas pedagógicas.

Para finalizar, gostaria de dizer que, desde o início do curso, os docentes estão construindo com os estudantes bases de articulação interepistêmicas, a partir de referenciais inauguradores, tais como pedagogia da retomada, prolongar conhecimentos, articular saberes, relembrar saberes, frequentar a língua materna, atualização cultural, bilinguismo epistêmico, documentação de saberes pelo fazer cultural, juntar conhecimento, descobrir conhecimento. Todos esses conceitos surgiram na articulação dos conhecimentos produzidos nos Projetos Extraescolares, nos Estágios, na Ação Saberes Indígenas na Escola e até mesmo 
na sala de aula. Todos esses conceitos dialogam com a Pedagogia do Oprimido, da indignação, da libertação de Paulo Freire; com a Desobediência Epistêmica de Catherine Walsh e Walter Mignolo; com a Ecologia de Saberes, de Boaventura Sousa Santos, demonstrando que a coteorização é um processo contínuo e que o importante disso é que todos se sentirão autores e protagonistas de seu processo de formação e da sua docência.

As matrizes curriculares dos projetos político-pedagógicos já produzidos e dos que estão em produção devem se iluminar por essas orientações epistêmicas. Todas elas se situam no mesmo construto de inspiração e de comprometimento com as lutas indígenas e, consequentemente, com as lutas anticoloniais. A coteorização é uma luta anticolonial, por isso ela é emergente e necessária. Ela é um movimento contínuo e que atende às demandas da decolonização dos saberes indígenas, das escolas indígenas e da criação de novos conhecimentos na educação intercultural.

\section{Sobre a autora:}

Lilian Abram dos Santos: Mestre em Linguística. Doutora em Linguística Aplicada. Docente da área de Linguagens do Núcleo Takinahakỹ de Formação Superior Indígena, da Universidade Federal de Goiás (UFG). E-mail: Iiliabram@gmail.com, Orcid: http://orcid.org/0000-0001-8444-9283

Recebido em 27 de fevereiro de 2020.

Aprovado para publicação em 9 de junho de 2020. 